\title{
Non-thermal Plasma Treatment of Rowing Water: A Solution to Reduce Water Usage and Soil Treatment Cost without Compromising Yield
}

\author{
J. Brar, ${ }^{a}$ J. Jiang, ${ }^{a}$ A. Oubarri, ${ }^{b}$ P. Ranieri, ${ }^{b}$ A. Fridman, ${ }^{b}$ G. Fridman, ${ }^{b}$ V. Miller, ${ }^{b} \&$ \\ B. Peethambaran ${ }^{a}$, \\ ${ }^{a}$ Department of Biological Sciences, University of Sciences, Philadelphia, PA 19104; ${ }^{b}$ C. \& J. \\ Nyheim Plasma Institute, Drexel University, Camden, NJ 08103 \\ *Address all correspondence to: Dr. Bela Peethambaran, 600S 43rd Street, Philadelphia, PA 19104; Tel.: 215-596-8923; \\ Fax: 215-596-8710, E-mail: b.peethambaran@usciences.edu
}

\begin{abstract}
Water scarcity and drought have become increasingly larger problems because of the changing climate and exploding human population. According to the United Nations, by 2025, 2 million people will be affected by the lack of clean drinking water. Agriculture accounts for nearly $70 \%$ of the consumption of the Earth's freshwater supply. Hence, there is an increased effort to improve plant irrigation without compromising plant yield. The goal of this research study is to determine the effects of using non-thermal plasma technology (NTPT) on Arabidopsis thaliana plants to tolerate drought and reduce water usage. Treatment of flowing water with non-thermal plasma (NTP) on A. thaliana plants showed that they could tolerate longer periods of dehydration and required less water. There was a significant decrease in the amount of NTP-treated water consumed, and the plants had more flowers and seeds compared to control plants. The study also monitored molecular changes in the NTP-treated plants that could have contributed to the increased tolerance to drought.
\end{abstract}

KEY WORDS: drought tolerance, Arabidopsis thaliana, water conservation

\section{INTRODUCTION}

Changing climate and increasing population have led to a major water crisis. In January 2015, The World Economic Forum stated that the water crisis is the number one risk to global society and has the potential to devastate millions of people. ${ }^{1}$ According to the United Nations, nearly one-fifth of the world's population, or 1.2 billion people, live in areas that are impacted by water scarcity. This number is expected to increase by 2025 , and it is estimated that nearly 2 billion people will be affected by the lack of clean drinking water. ${ }^{2}$ This water crisis also has a major impact on availability of water for irrigation. Agriculture accounts for nearly $70 \%$ of the consumption of Earth's freshwater supplies. ${ }^{2}$ Currently, $25 \%$ of the world population does not have enough water to properly irrigate their crops. ${ }^{3}$ This problem is compounded by frequent droughts due to climate change and emission of greenhouse gases, resulting in a lack of rainfall. The Intergovernmental Panel on Climate Change estimates that by the year 2020, there will be a 50\% reduction in plant yield due to drought and arid conditions in African countries, leading to a $90 \%$ 
reduction in revenues. ${ }^{4}$ Hence, there is an increased effort to improve and manage plant irrigation under drought conditions. Current methods to address this situation are addition of fertilizers or use of genetically modified seeds. However, the long-term impact of these techniques on health and environment are a major concern. Most nurseries and greenhouses require a large and continuous supply of water, and these are often near or within the boundaries of major urban areas. ${ }^{5}$ Hence, these agricultural production units undergo stiff competition for water supplies and scrutiny on the potential environmental impact of their water discharges. These issues are prevalent across all eco-geographic regions, from sites where precipitation is relatively abundant to the most arid regions of the country. The added cost of remediating the harmful impacts of fertilizer on soil is a major economic burden. Our proposed solution to the problems of bioremediation and a lack of fresh water for agriculture is the non-equilibrium cold plasma treatment of flowing water.

Plasma, the fourth state of matter, is a partially (non-equilibrium plasma) or completely (equilibrium plasma) ionized gas, and it represents a highly reactive and highly energetic medium. In the laboratory, plasma can be generated by applying high voltage between two conductive electrodes. In this paper, non-equilibrium plasma, frequently referred to as non-thermal plasma (NTP), is generated by creating a thermal arc between two concentric metal pipes and cooling it rapidly with fast air flow. This increases the volume of plasma and decreases gas temperature to the point where water can be treated in such a system, previously described by the authors. ${ }^{6,7}$ This non-thermal plasma treatment (NTPT) of water generated relatively high concentrations of reactive oxygen species (ROS) and reactive nitrogen species in water, and then this water can be used for further application to soil.

Plasma has shown promise in improving crop yield by improving germination even under drought conditions. Studies have demonstrated that the cold plasma treatment enhanced germination rates by $6.25 \%$ in plants under drought conditions. ${ }^{8}$ Water treated with plasma has been used to grow spinach, tomatoes, and pepper plants, and it was reported that the treatment increased the yield of these plants. ${ }^{6}$ Loss of crop yield due to pathogen infection is another major agricultural problem. Cold plasma treatment has been shown to significantly decrease the presence of both Aspergillus spp. and Penicillium spp. of fungi. ${ }^{9}$ An earlier study demonstrated that irrigation of Arabidopsis thaliana plants with NTPT water decreases the amount of water required and increases yield compared to plants irrigated with deionized (DI) water. Cold plasma treatment of water for irrigating Arabidopsis has shown to be effective in decreasing water consumption. ${ }^{10}$ There was $30 \%$ more retention of moisture in the soil of the pots that were watered with plasma compared to controls, which potentially led to decreased consumption of water to achieve $80 \%$ or more moisture levels in water. ${ }^{10}$ These data indicate that plants could survive with $30 \%$ less water and hence be more tolerant to drought stress. Our study here focuses on the ability of plasma treatment of water to increase plant tolerance to drought conditions.

In this study, we hypothesize that plasma treatment of water would decrease water needs of plants and prepare plants for drought conditions without compromising their 
yield. For this, Arabidopsis plants were treated with simulated drought conditions, and the changes in their physiology in certain stress-related genes were investigated.

\section{MATERIALS AND METHODS}

\section{A. Plasma Treatment}

Non-equilibrium gliding arc plasma in air was used to treat the water on the same day as administration to plants, as described by Peethambaran et al. ${ }^{10}$ This NTPT treatment generated $>100 \mathrm{ppm}$ of $\mathrm{O}_{2}^{-}, 40-80 \mathrm{ppm} \mathrm{NO}_{2}$, and 100-250 ppm $\mathrm{NO}_{3}^{-}$. The water generated from this treatment had a pH of $\sim 3-4$. The NTPT-treated water was delivered to the plant incubation site within an hour of treatment. The reactive oxygen species concentration was still $>100 \mathrm{ppm}^{-} \mathrm{O}_{2}^{-}$, whereas the $\mathrm{NO}_{2}{ }^{-}$had dropped to less than $40 \mathrm{ppm}$, and $\mathrm{NO}_{3}^{-}$remained at 100-250 ppm by the time this water was applied to the plants.

\section{B. Plant Growth Conditions}

A. thaliana were planted in pots using Sunshine Mix (Sun Gro Horticulture, Quincy, $\mathrm{MI}$ ), and incubated in an environmental growth chamber maintained at $24^{\circ} \mathrm{C}$ with $70 \%$ relative humidity and a 12-hour photoperiod. The wild type (Columbio-0) seeds were suspended in $1 \%$ agar and cold treated in $4^{\circ} \mathrm{C}$ for 3 days before seeding them in soil.

\section{Planting Design}

A total of 96 A. thaliana plants were planted. Out of the 96 plants, 48 of them were treated with NTPT water, and 48 were watered with deionized water for 4 weeks. At week 5, the 48 plants from the plasma treated group were divided into two groups of 24 plants. One group was called "plasma wet" and the other called "plasma drought." The same procedure was repeated for the control plants, totaling four groups. The "plasma wet" and "control wet" continued to be watered with plasma water or DI water respectively. The two "dry" groups were subjected to drought conditions (stopped watering) until the soil had $<30 \%$ moisture.

\section{Watering Schedule}

For weeks 1-4, the "plasma group" tray was watered with plasma-treated water, and the "control group" plants were irrigated biweekly with DI water. Before watering, the soil moisture was measured using a soil moisture meter (Mudder 3-in-1 Soil Moisture Meter), and water was added to the pots until the soil was $85 \%-90 \%$ saturated. The amount of water used was noted to calculate the total amount of water used. At week 5 , the "plasma dry" and "control dry" trays no longer received water, whereas the "plasma wet" and "control wet" were watered the same way they had been in weeks $1-4$. The drought simulation for 24 plants from the "plasma dry" and "control dry" trays contin-

Volume 6, Issues 3-4, 2016 
ued until the moisture in the soil was $<30 \%$. Leaf tissues were collected in liquid nitrogen for further assays to investigate enzymatic activity of catalase and nitrate reductase.

\section{E. pH Measurement of NIPTWater and Soil}

The $\mathrm{pH}$ of the NTPT water was recorded right after plasma treatment. The plasmatreated water was used to irrigate plants after $30 \mathrm{~min}$, and the $\mathrm{pH}$ of the NTPT water was again observed to achieve a $\mathrm{pH}$ of 5.5-6.5. The $\mathrm{pH}$ of the soil was measured before and after every watering using the Mudder 3-in-1 Soil Moisture Meter.

\section{F. Measuring Nitrate Levels in Soil and Water}

The nitrate levels in the soil were measured using nitrate strips (Fisher Scientific, Portsmouth, NH). The nitrate levels were checked both before watering and then 15 minutes after watering. This was done prior to every biweekly watering of the pots. To measure nitrates, $1 \mathrm{~g}$ of soil was removed from five randomly selected plants from each of the four trays. The soil sample was placed in $10 \mathrm{~mL}$ of drinking water, which has less than $2 \mathrm{ppm}$ of nitrate, to make a slurry solution, and a nitrate strip was used to measure the nitrate content. After a minute, the nitrate content was read and matched to the grade given by Fisher Scientific.

\section{G. Leaf Area}

The leaf area of the control and plasma treated plants were measured weekly by taking pictures and analyzing the area using the software ImageJ.

\section{H. Seed Pod, Petal Count, and Plant Height}

The number of seed pods and number of flower petals were recorded starting at week 5 and continued for the rest of the experiment. Five plants were randomly selected from each of the four trays and measured weekly. The plants that were used for counting during a particular week were not used in the following week. Similarly, the height of the plants was recorded starting at week 5, and measurements were made in centimeters. Five plants were selected from each of the four plants for measuring on a weekly basis. If a plant was used for measuring during a particular week, it was not used again the following week.

\section{Nitrate Reductase and Catalase Activities}

A nitrate reductase assay and the catalase activity were performed using the techniques outlined by Pessarakli and Kopec. ${ }^{11}$ For the nitrate reductase activity, leaf samples were obtained from plants in the NTPT-treated and control groups, 1 day after watering. They were placed in liquid nitrogen and treated with polyvinylpolypyrrolidone (PVP) and extraction buffer containing $0.2 \mathrm{M}$ Tris- $\mathrm{HCl}, 1 \mathrm{mmol}$ ethylene diamine tetra acetic acid 
(EDTA), $5 \mu \mathrm{mol}$ flavin adenine dinuleotide (FAD), and $2 \beta$-mercaptoethanol per liter to prepare a crude extract of the enzyme. The activity of the enzyme was determined using nicotinamide adenine dinucleotide phosphate (NADPH) and a spectrophotometer at wavelength $540 \mathrm{~nm}$. For the catalase activity, $15 \mu \mathrm{L}$ of the catalase enzyme extract was added to $1 \mathrm{~mL}$ of potassium phosphate buffer and $2.5 \mu \mathrm{L}$ of $30 \% \mathrm{H}_{2} \mathrm{O}_{2}$. A reading on the spectrophotometer was made at $240 \mathrm{~nm}$, and catalase activity was measured in micrograms/fresh weight.

\section{J. Statistical Analysis}

Data was collected for 8 weeks for all 96 plants ( 24 plants in each of the four treatment groups). The data were analyzed using paired $t$-tests to determine the significance of results.

\section{RESULTS}

\section{A. Impact of NIPTWater on the Growth and Yield}

The height of the plants stalk was measured during weeks 5-7 (Fig. 1). There was significant difference in the height on plants treated with NTPT water compared to all other

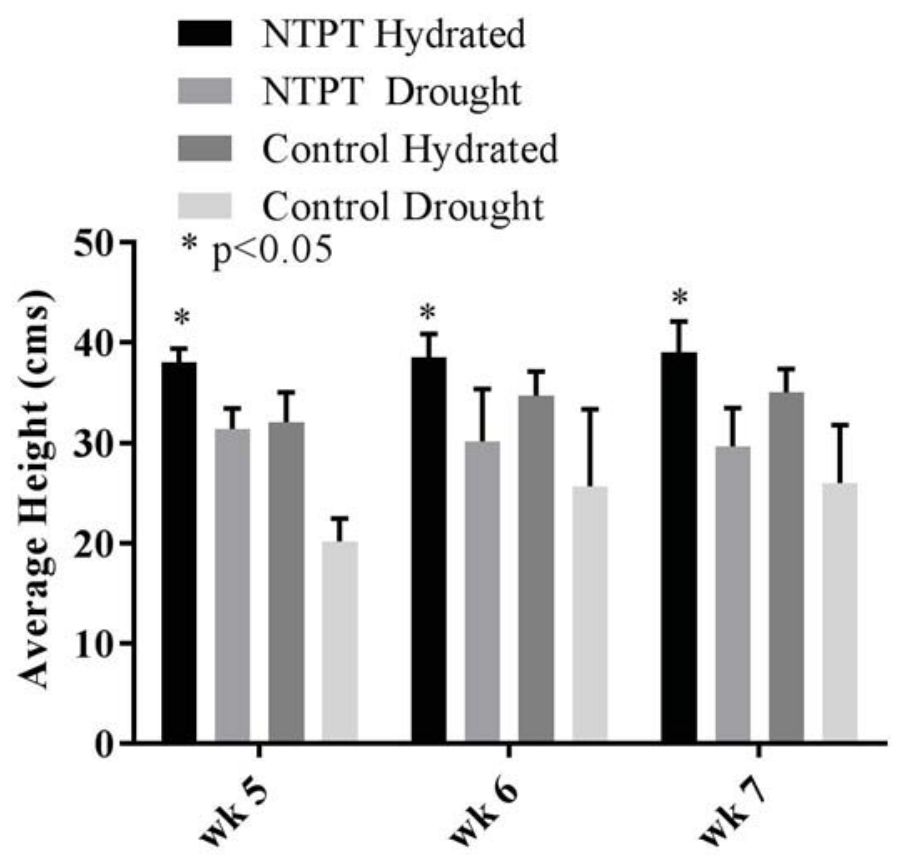

FIG. 1: Graph represents average \pm SD of height of stalks for weeks 5-7. The error bars represent standard deviation.

Volume 6, Issues 3-4, 2016 
groups. The NTPT plants, which were drought simulated at week 5, had similar height to control hydrated plants. The plants with least height were the control plants that were drought treated on week 5 , showing reduction in growth. The leaf area was measured using ImageJ. It was observed that the leaves from plants treated with plasma water were bigger in size representing increased biomass (Fig. 2).

Drought simulation of the plants that were watered with plasma treated water for 4 weeks had a greener phenotype (B) compared to controls that were watered with deionized water (c) (Fig. 3).

The flowers and seeds were counted for the pots that were hydrated during weeks 5-7 in both the control and plasma trays ( 24 in each) and were averaged. The number of flowers are significantly higher in the plasma-treated plants than the control (Fig. 4). Under drought stress, plants that were watered with NTPT water had an average number

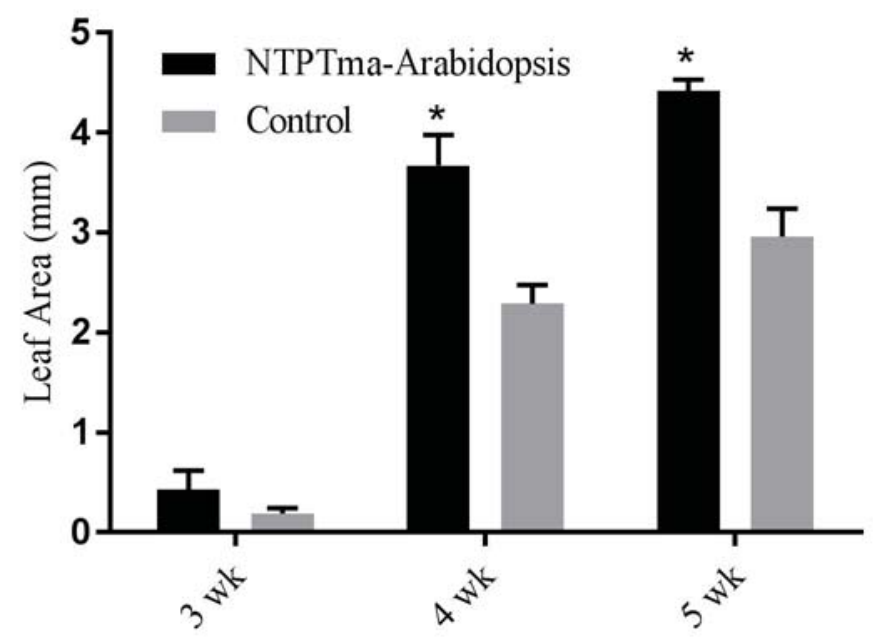

FIG. 2: Graph represents average $\pm \mathrm{SD}$ of leaf area for weeks 2-7. The error bars represent standard deviation.

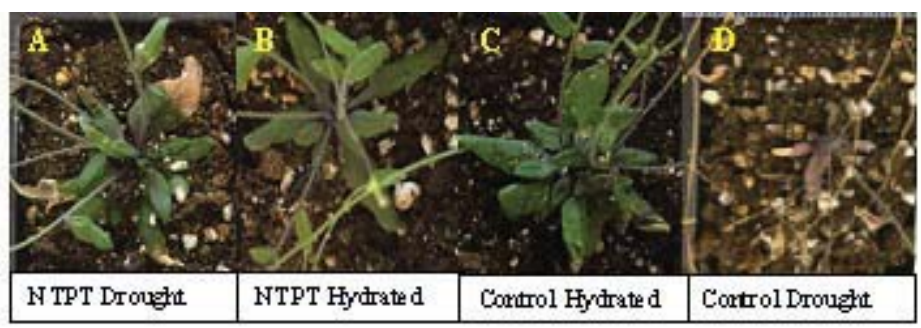

FIG. 3: The plants shown here are 6 weeks old. They have been irrigated with NTPT water for 4 weeks (A) and drought treated for 1 week, in contrast to the plants that are either continuously hydrated with NTPT-treated water (B) or DI water (C). The picture in D shows control plants post drought treatment. 


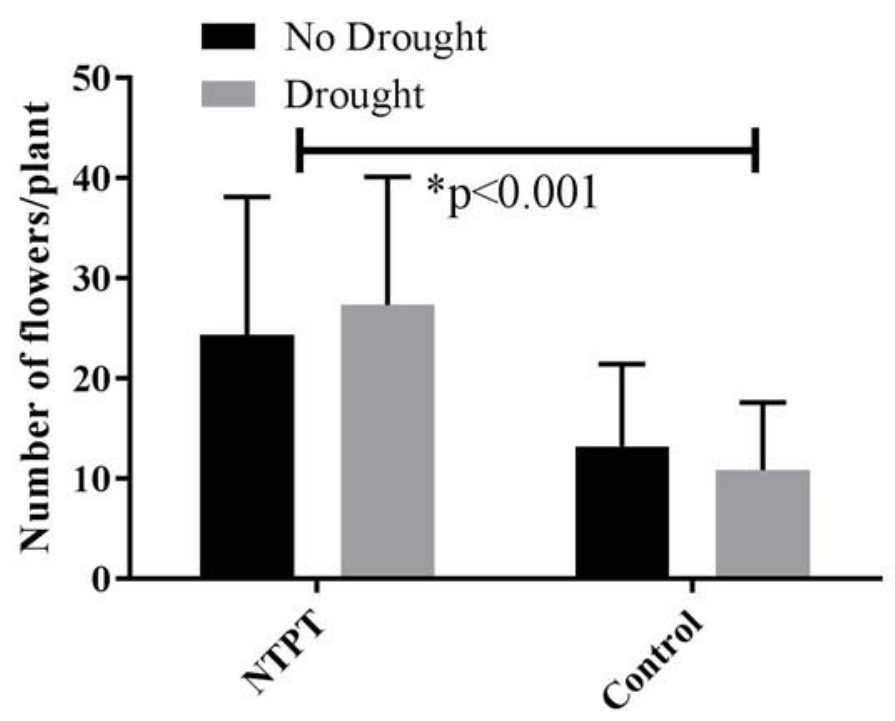

FIG. 4: Graph represents average \pm SD of flower yield for weeks 5-7 under drought conditions and in normal watering schedule. The error bars represent standard deviation.

of flower $(25 \pm 15)$ similar to that from the NTPT plants that were watered regularly, but these flower numbers were high compared to control hydrated and drought-treated plants. This result shows that NTPT plants had significantly high yield of flowers even under drought stress. For the seed count, the NTPT watered plants had more seeds compared to drought treated NTPT plants (Fig. 5). In drought stress, the NTPT plants produced more seeds than the control plants that were also drought simulated. These data show that the plasma-watered plants that were drought stressed could produce a yield comparable to plants that were watered with plasma water. There was no effect of the drought stresses on the yield of the NTPT plants.

\section{B. Increased Drought Tolerance in Plants Watered with NIPT}

To understand the effects of ROS present in plasma water on plants, we determined the activity of a known ROS scavenging enzyme catalase. Figure 6 shows that catalase activity was twice as high in the NTPT watered plants compared to controls. The ROS could have also acted as stress signals that stimulated defense responses of $A$. thaliana to tolerate drought conditions.

\section{Water Consumption of A. thaliana Plants Treated with Plasma}

The water consumption was almost reduced to $\sim 30 \%$ every week (Fig. 7). After week 5 the average included only those pots that were not drought simulated and kept hydrated (24 pots each group). The plants irrigated with plasma water consumed approximately

Volume 6, Issues 3-4, 2016 


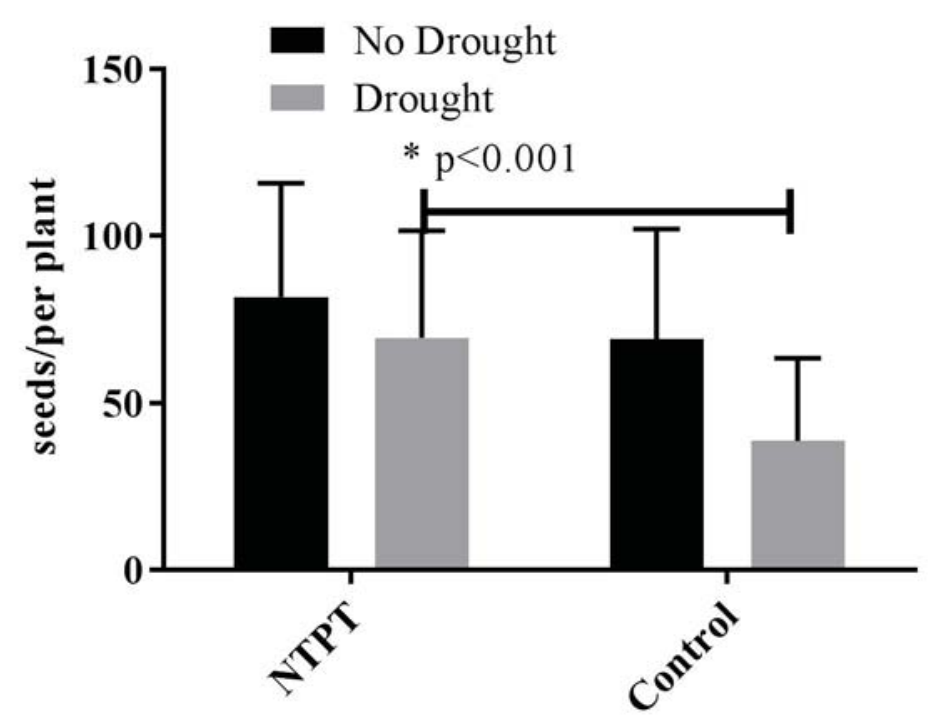

FIG. 5: Graph represents average \pm SD of seeds counted in weeks 5-7 plants that were drought stressed and watered regularly. The error bars represent standard deviation.

\section{catalase}

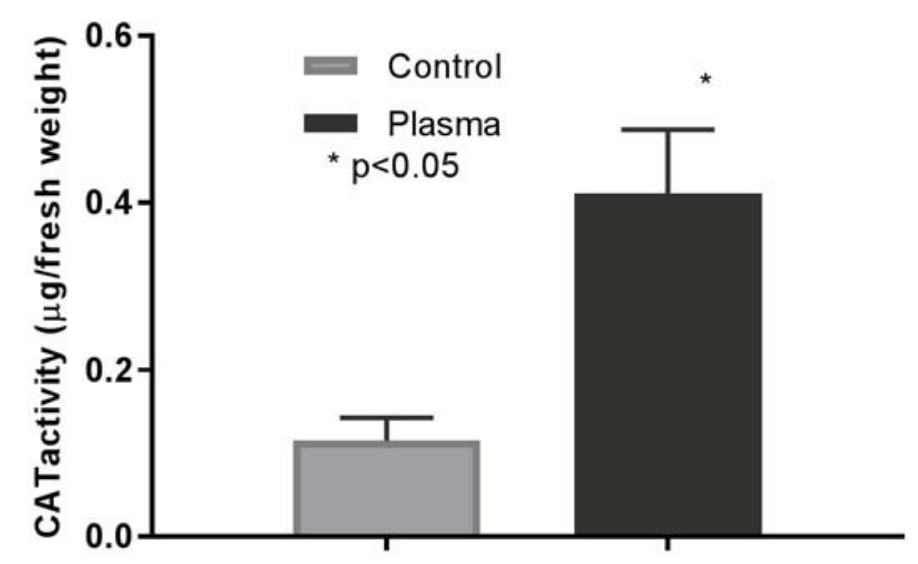

FIG. 6: The catalase activity showed a significantly higher level of catalase (two times more) in plasma crops compared to the controls. The graph shows average \pm SD of five readings in leaves collected from 3-week-old plants.

$30 \%-40 \%$ less water than the controls. Water was added to the soil only after measuring the moisture, and just enough water was added to saturate the soil up to $85 \%-90 \%$. The biweekly watering for every week after week 2 shows significant reduction in water consumption. 


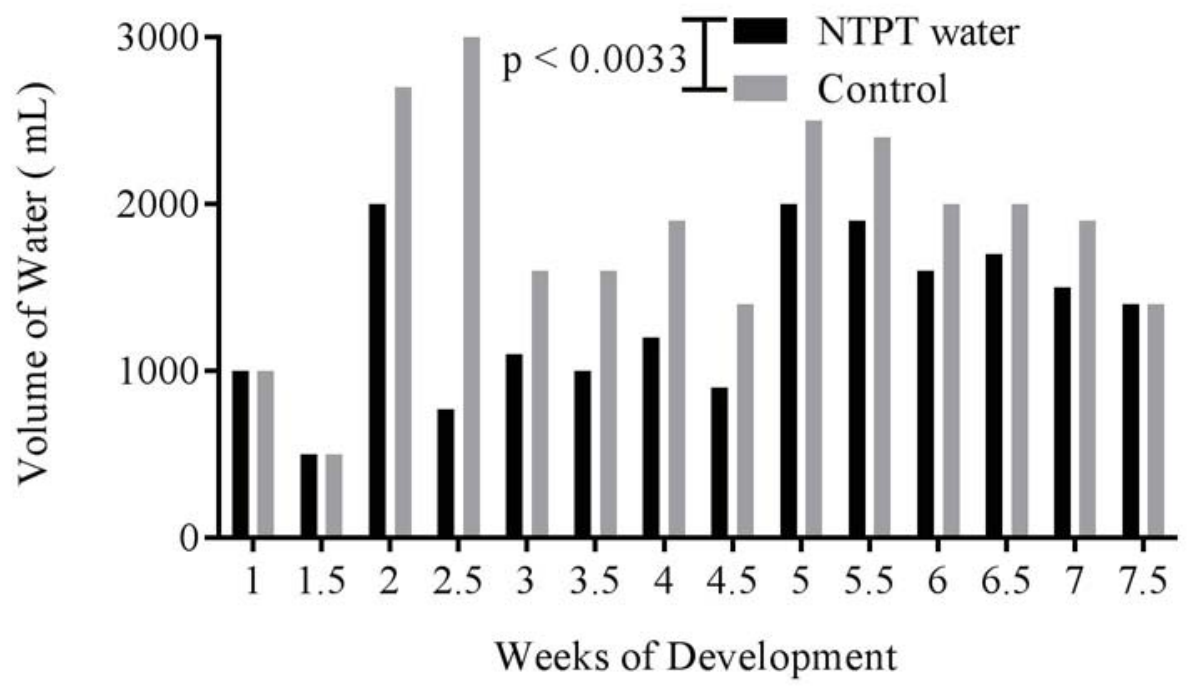

FIG. 7: Amount of water in liters used biweekly to irrigate pots in the control and plasma group from weeks 1-7.5. After week 5, the numbers include only those groups that were kept hydrated.

\section{Moisture Content in Soil}

Figure 8 shows that the soil treated with plasma retained approximately $25 \%$ more moisture in the soil than the control crops. The high soil moisture content resulted in lower consumption of water, as shown in Fig. 7. After week 5, the moisture was measured in

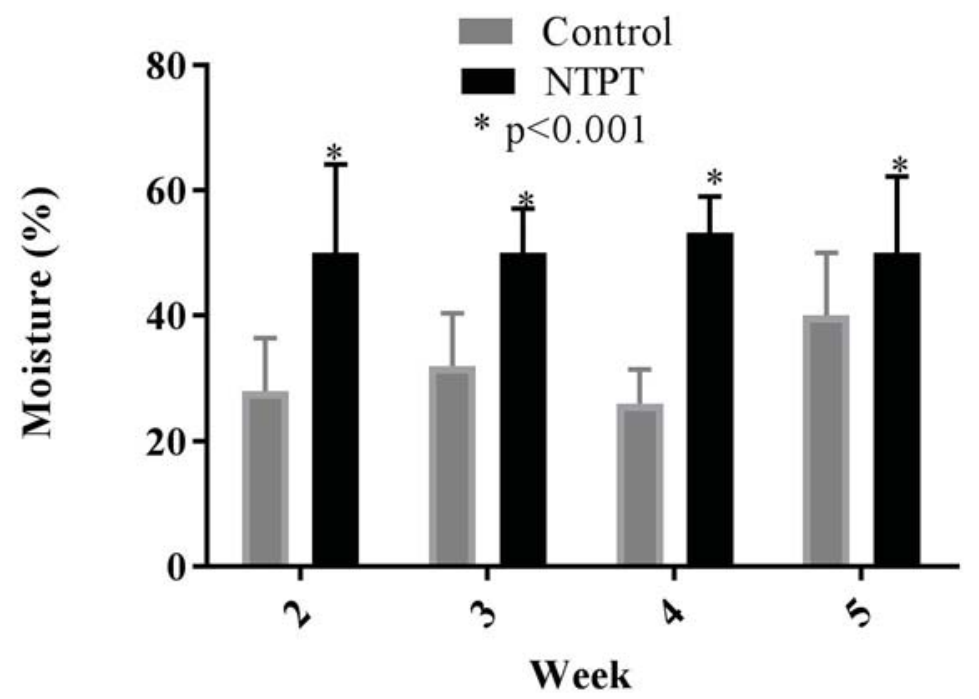

FIG. 8: The average $\pm \mathrm{SD}$ of soil moisture of pots irrigated with NTPT water versus control. The error bars represent standard deviation.

Volume 6, Issues 3-4, 2016 
24 pots from control and plasma group that were deprived of water. Figure 9 shows that within the drought group, the plasma crops retained significantly higher moisture in the soil than the control crops. Similarly, in the pots that were hydrated with DI water or with NTPT water, there was significantly higher moisture in the soil for the plasmatreated crops compared to the control. Moisture content dropped in the drought-treated NTPT pots to $\sim 20 \%$, but it was significantly higher than in the control pots.

To determine if the leaves were holding more moisture after being irrigated with NTPT water, absolute water content was measured.

Figure 10 shows the average \pm standard deviation (SD) of the absolute water content measured in 20 leaves from 20 different plants that were treated with NTPT water and the control. The graph also represents differences in the absolute water content observed in plants that were drought simulated and were treated with NTPT water for 5 weeks, versus control plants that were also drought treated.

There was no difference in the absolute water content of leaves treated with control DI water or with NTPT water. However, there was significantly higher relative water content in the leaves of the plants that were NTPT watered for 5 weeks and then drought treated as compared to the control drought plants.

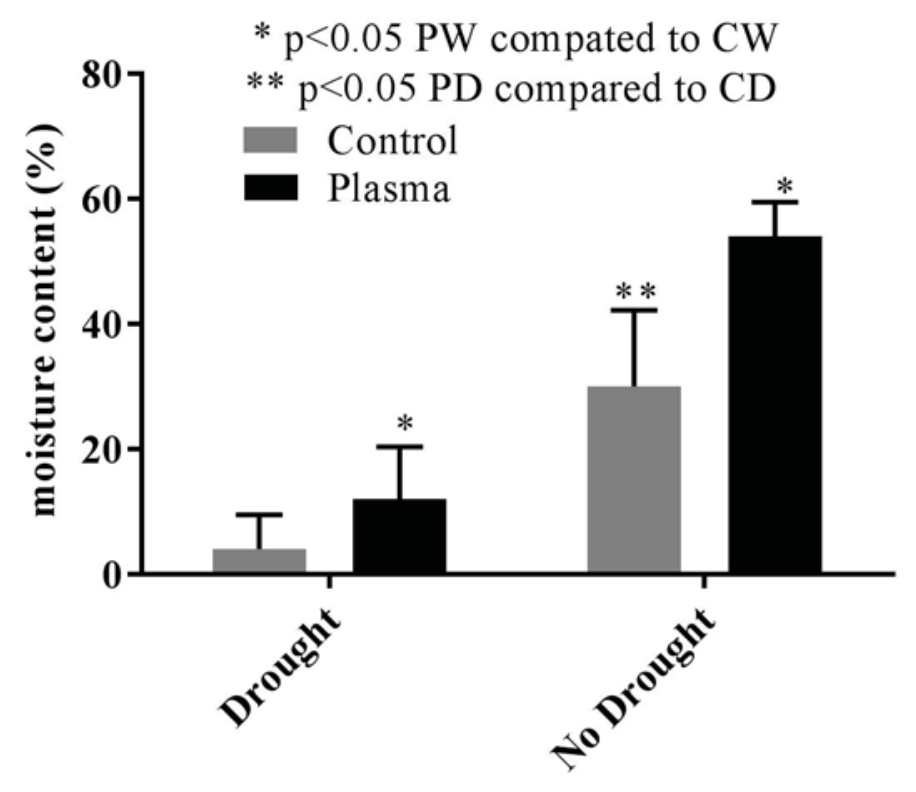

FIG. 9: The average \pm SD of soil moisture of pots irrigated with NTPT water versus control in drought simulation and in hydration after week 5 . The error bars represent standard deviation. 


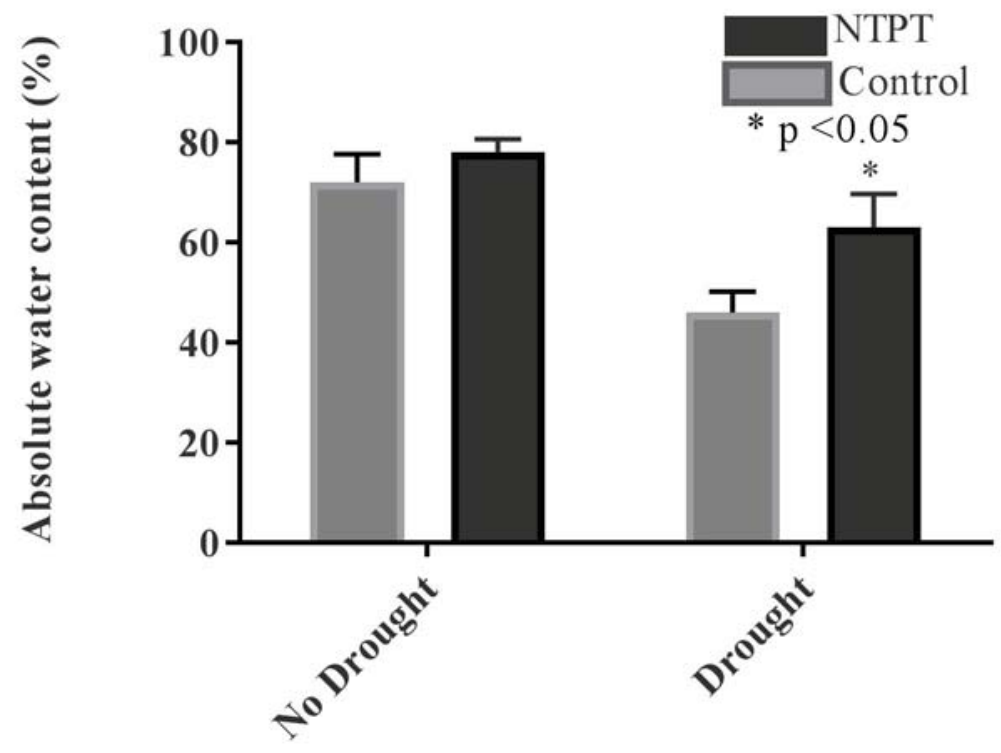

FIG. 10: The average $\pm \mathrm{SD}$ of the absolute water content measured in 20 leaves from 20 different plants that were treated with NTPT water and the control. The graph also represents differences in the absolute water content observed in plants that were drought simulated and were treated with NTPT water for 5 weeks versus control that were also drought treated.

\section{E. Effect of Reactive Species on NTPTSoil}

Figure 11 shows nitrate levels in the soil 1 day post watering, and then remeasured 3 days after the watering to show depleting nitrate levels in soil. The figure shows average \pm SD of nitrate levels in the soil of three plants measured from week 2-5.

The nitrate levels in the soil were almost three times higher for the plasma-treated plants 1 day after watering compared to the controls. However, the reactive nitrogen species were transient, as they were reduced to $\sim 20 \mathrm{mg} / \mathrm{L}$, which is similar to the nitrate levels in the control water. To determine if the NTPT-treated plants sequestered the nitrates, nitrate reductase activity was measured. Nitrate reductase was significantly higher (fourfold) in the plasma crops than the controls (Fig. 12). It is possible that the nitrates from the plasma-treated water could be converted to ammonia and sequestered by the plants.

There was an almost sixfold increase in the nitrate reductase activity in the plants treated with plasma water, which may have resulted from sequestering of nitrates leading to increased growth.

\section{F. pH of the Soil in Plasma Treated Crops}

Figure 13 represents average $\pm \mathrm{SD}$ of the $\mathrm{pH}$ of the soil measured in plasma watered pots on the day of watering and 3 days post watering.

Volume 6, Issues 3-4, 2016 


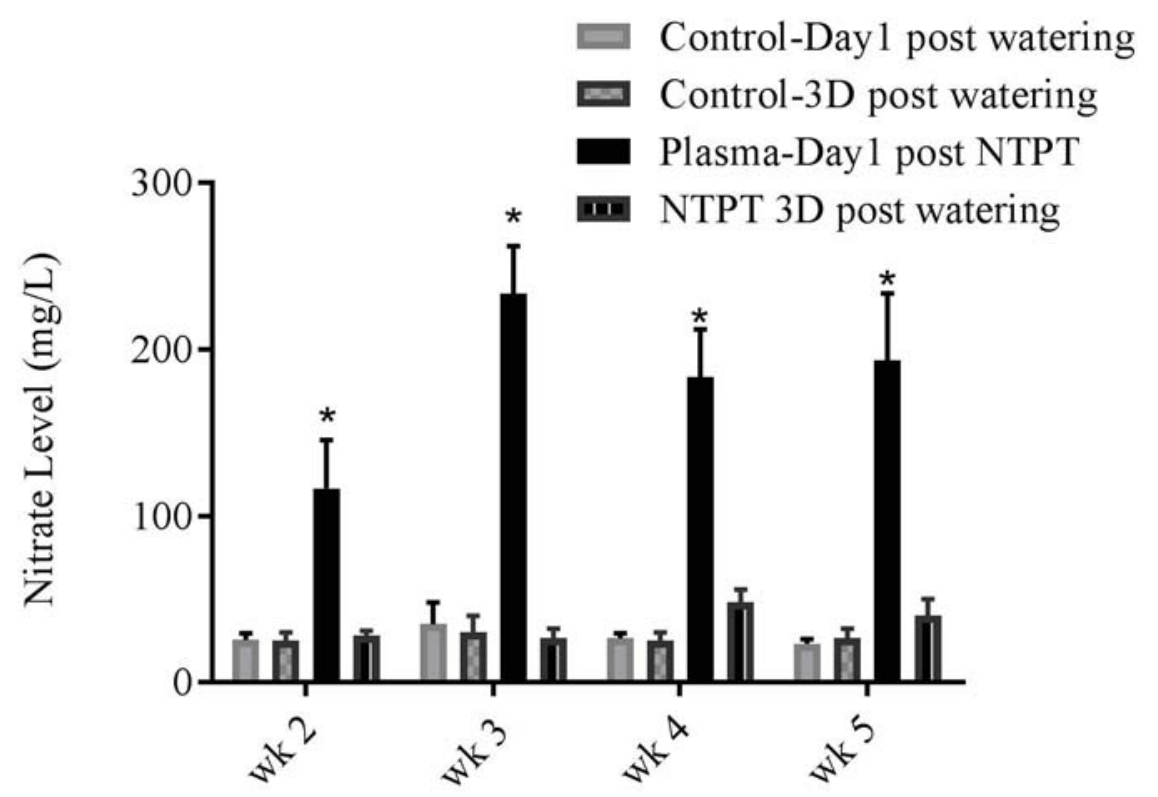

FIG. 11: Nitrate levels in the soil one day post watering and then re-measured 3 days after the watering to show depleting nitrate levels in soil. The figure shows average \pm SD of nitrate levels in soil of three pots measured in weeks $2-5$.

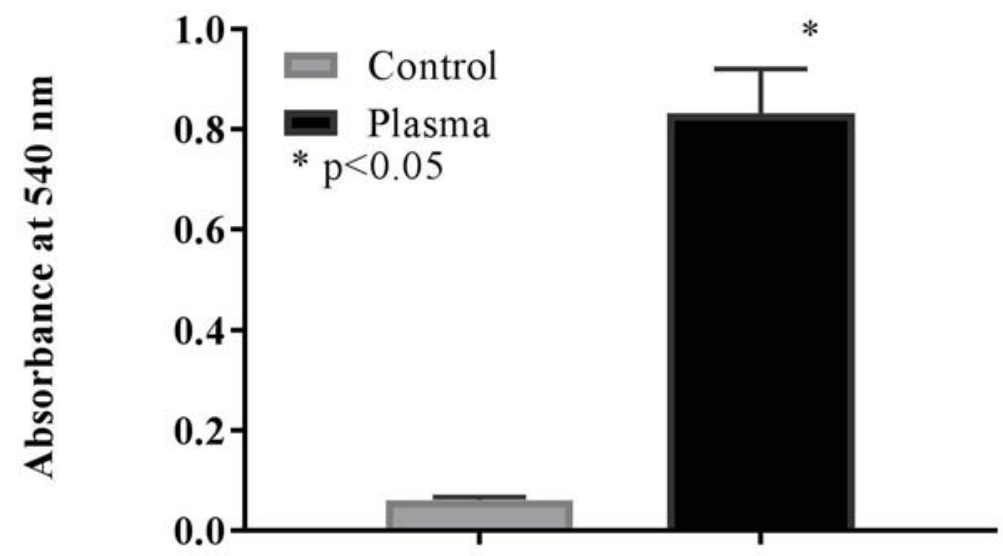

FIG. 12: Nitrate reductase activity in the leaves of plants treated with NTPT water on day 1 after watering versus control plants. The values expressed here are average \pm SD of nitrate reductase activity in five leaves from five different plants that were watered with NTPT-treated water. 


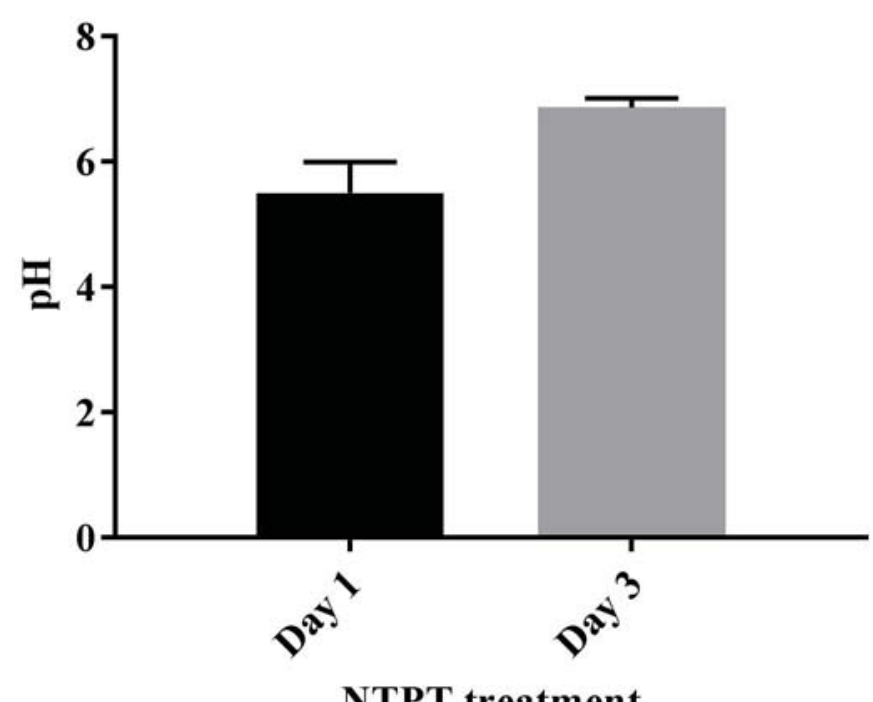

FIG. 13: Represents average $\pm \mathrm{SD}$ of the $\mathrm{pH}$ of the soil measured in plasma-watered pots on the day of watering and 3 days post watering

One day after watering, the $\mathrm{pH}$ in the soil of the plasma crops was around 5.5; this mildly acidic condition is optimal for the growth of A. thaliana. Three days after watering, the $\mathrm{pH}$ returned to a neutral 7. The acidic $\mathrm{pH}$ of the plasma water is due to presence of ions generated by plasma. Depletion of ions post watering reduces the residual nitrogen ions while neutralizing the $\mathrm{pH}$ of the soil.

\section{DISCUSSION}

Use of plasma-treated flowing water improved growth and yield in A. thaliana plants, even under drought conditions. This could be due to presence of reactive nitrogen species generated in the plasma-treated water, because it is could be sequestered in plants. This was demonstrated by the increased activity of nitrate reductase. The plants treated with NTPT water also showed higher tolerance to drought simulation without compromising the growth and yield. One possible reason for this is the ROS generated by plasma treatment. Plasma generates ROS, including singlet oxygen $\left({ }^{1} \mathrm{O}_{2}\right)$, superoxide radical $\left(\mathrm{O}_{2}{ }^{-}\right)$, hydrogen peroxide $\left(\mathrm{H}_{2} \mathrm{O}_{2}\right)$, and hydroxyl radical $(\mathrm{HO} \bullet)$. If ROS are introduced into the plant in large amounts, oxidation will occur, damaging DNA, RNA, and macromolecules, which ultimately damages cells. However, in small quantities, ROS are able to signal that the plant is stressed, thus eliciting a response from the plant immune system to protect itself from drought. ${ }^{12}$ ROS could be serving as a signaling molecule in the cells and finely modulating the plants to activate defense response..$^{13}$ It has been previously shown that priming to ROS for tolerance to abiotic stress, such as salt in citrus, increased the abundance of oxidized and $S$-nitrosylated proteins and resulted in higher tolerance

Volume 6, Issues 3-4, 2016 
to salt stress. ${ }^{14}$ Since we found the ROS to be transient in plants, we propose that $A$. thaliana ROS may have been signaling molecules that triggered a defense response, thus contributing to a plant's ability to tolerate drought conditions. The A. thaliana treated with plasma did not show any signs of stress. Previous studies have established that cold plasma can activate vitality of seeds, and improve growth and yield in several crops, such as wheat, tomatoes, and peppers, without causing any mutations. ${ }^{15}$ Other evidence that suggests plasma water is activating plant defenses is when plasma-treated water is used to wash plant produce, resulting in reduced bacterial and fungal contamination. ${ }^{16}$ This effect was also due to activation of plant defense-related genes. Drought tolerance in plants occurs through a defense pathway that is also activated during pathogen attack. ${ }^{13}$ Hence, under drought simulated conditions plants watered with NTPT-treated water resisted drought conditions without compromising the quantity and quality of the yield.

The other possible reason for A. thaliana plants treated with NTPT to resist drought is due to the high soil moisture retention. The relatively high concentration of ions in NTPT water, such as $\mathrm{N}_{4}^{+}$and $\mathrm{O}_{2}^{-}$, increases surface energy of the soil and attracts polar water molecules to remain attached to this soil. However, further investigations on the effects of plasma water on soil are warranted. We have demonstrated here that use of the gliding arc discharge technology for plasma treatment of flowing water is a possible technological solution to conserve water used in agriculture and also to develop plants that can resist long periods of water deprivation.

Effects of plasma water in supplementing soil with nitrates and slightly acidic $\mathrm{pH}$ has proved conducive for growth of A. thaliana. Nitrate reductase activity is generally seen in roots of plants; however, higher nitrate reductase activity is measured in leaves of weeds. Hence, the leaves of A. thaliana treated with plasma water were collected to measure activity of nitrate reductase. The higher activity of nitrate reductase in NTPT plants complemented with decreasing nitrate levels in soil indicates that nitrates supplied by plasma water are being used by plants and contributes to increased growth. However, a study on which parts of plants have higher accumulation of nitrates and the effects of nitrates on photosynthesis in NTPT plants is warranted. We also observed that the $\mathrm{pH}$ of the NTPT-treated soil reverts from acidic $\mathrm{pH}$ to $\mathrm{pH} \sim 7$ by the third day. This is advantageous especially in real farm settings where liming processes are carried out to neutralize the $\mathrm{pH}$ of acidic soil. The acidic $\mathrm{pH}$ of plasma water is beneficial for certain acidic water-loving plants.

\section{CONCLUSIONS}

Our study demonstrates that $A$. thaliana plants irrigated with plasma water for 3 weeks have a higher tolerance for drought. Plasma water-treated plants show increased growth and fecundity. Plasma technology offers an innovative solution to the water crisis by conserving water with increased growth of plants, reducing fertilizer and soil liming treatment costs. 


\section{REFERENCES}

1. Water.org. Water Facts: Facts About the Global Water Shortage. c1990-2017 [cited 2017 Mar 24]. Available from: http://water.org/water-crisis/water-sanitation-facts.

2. International Decade for Action 'Water for Life' 2005-2015 [homepage on the Internet]. New York: United Nations Department of Economic and Social Affairs [updated 2014 Nov 24; cited 2016 Sep 16]. Available from: http://www.un.org/waterforlifedecade/scarcity.shtml.

3. Kummu M, Ward PJ, de Moel H, Varis O. Is physical water scarcity a new phenomenon? Global assessment of water shortage over the last two millennia. Environ Res Lett. 2010;32(5):1-9.

4. Boubacar I. The effects of drought on crop yields and yield variability in Sahel. Southern Agricultural Economics Association Annual Meeting, Orlando, FL, February 6-9, 2010 [cited 2017 Mar 24]. Available from: http://ageconsearch.umn.edu/bitstream/56322/2/crop yield.pdf.

5. Bartok JW. Sizing the greenhouse water system. Center for Agriculture, Food and the Environment. 2016 [cited 2017 Mar 24]. Available from: https://ag.umass.edu/greenhouse-floriculture/fact-sheets/ sizing-greenhouse-water-system.

6. Park D, Davis K, Gilani S, Alonzo CA, Dobrynin D, Friedman G, Fridman A, Rabinovich A, Fridman G. Reactive nitrogen species produced in water by non-equilibrium plasma increase plant growth rate and nutritional yield. Curr Appl Phys. 2013;29(13):19-29.

7. Fridman G, Friedman G, Gutsol A, Shekhter AB, Vasilets VN, Fridman A. Applied plasma medicine. Plasma Process Polym. 2008;25(6):503-33.

8. Ling L, Jiangang L, Minchong S, Chunlei Z, Dong Y. Cold plasma treatment enhances oilseed rape seed germination under drought stress. Sci Rep. 2015;5:13033.

9. Panngom K, Lee SH, Park DH, Sim GB, Kim YH, Uhm HS, Park G, Choi EH. Thermal plasma treatment diminishes fungal viability and up-regulates resistance genes in a plant host. PLoS One. 2014;9(6):e99300.

10. Peethambaran B, Han J, Kermalli K, Jiaxing J, Fridman G, Balsamo R, Fridman AA, Miller V. Nonthermal plasma technology (NTPT) reduces water consumption while accelerating Arabidopsis thaliana growth and fecundity. Plasma Med. 2016;5(4):87-98.

11. Pessarakli M, Kopec DM. Competitive growth responses of three cool-season grasses to salinity and drought stresses. Acta Hortic. 2008;783:169-74.

12. de Carvalho MHC. Drought stress and reactive oxygen species: production, scavenging and signaling. Plant Signal Behav. 2008;10(4161):156-65.

13. Rejeb IB, Pastor V, Mauch-Mani B. Plant responses to simultaneous biotic and abiotic stress: molecular mechanisms. Plants. 2014; 3:458-75.

14. Tanou G, Molassiotis A, Diamantidis G. Hydrogen peroxide- and nitric oxide-induced systemic antioxidant prime-like activity under $\mathrm{NaCl}$-stress and stress-free conditions in citrus plants. J Plant Physiol. 2009;16(6):1904-13.

15. Živković S, Puač N, Giba Z, Petrović ZL. The stimulatory effect of non-equilibrium (low temperature) air plasma pretreatment on light-induced germination of Paulownia tomentosa seeds. Seed Sci Technol. 2004;32(9):693-701.

16. Selcuk, M., Oksuz L, Basaran P. Decontamination of grains and legumes infected with Aspergillus spp. and Penicillium spp. by cold plasma treatment. Bioresour Technol. 2008;9(9):5104-9.

Volume 6, Issues 3-4, 2016 